\title{
Ferramenta didática ou guia curricular? Percepção de professores sobre o processo de escolha dos livros didáticos de Sociologia em escolas do Ceará
}

Manoel Moreira de Sousa Neto' Rosemary de Oliveira Almeida ${ }^{2}$ Márcio Kleber Morais Pessoa ${ }^{3}$

\section{Resumo}

Este artigo objetiva compreender as percepções dos professores de Sociologia quanto à escolha e uso dos livros didáticos em seis escolas públicas da rede estadual do Ceará. Parte-se da hipótese de que o livro didático é utilizado como referência pelos professores para a construção do plano de curso e não como ferramenta auxiliar da prática pedagógica, tornando-se guia curricular de Sociologia no Ensino Médio. Analisam-se critérios utilizados pelos professores para a escolha do livro, com parâmetro nas categorias: topicalismo, nominalismo e contextualismo (MEUCCI, 2014). Avaliam-se seis obras escolhidas no edital do Programa Nacional do Livro Didático (BRASIL, 20I5c) e entrevistas com professores da disciplina. Percebe-se que a escolha do livro relaciona-se com a demanda por conteúdos para a disciplina, em detrimento das características

I Professor, Secretaria de Educação do Ceará/SEDUC-CE. Mestre em Sociologia, pela Universidade Federal do Ceará. Professor supervisor do Programa Institucional de Bolsas de Iniciação a Docência/PIBID. Principal publicação: Sociologia e ensino no Ceará: novas perspectivas. In: HANDFAS, A.; MAÇAIRA. J. P.; FRAGA, A. B. (Org.). Conhecimento escolar e ensino de Sociologia: instituições, práticas e percepções. Rio de Janeiro: 7 Letras, 2015, V. I p. 240-25I. E-mail: manoelneto8I@hotmail.com.

2 Professora, Universidade Estadual do Ceará (UECE). Doutora em Sociologia (UFC). Coordenadora de área de Sociologia do PIBID. Principal publicação: Liuro: Mulheres que Matam: universo imaginário do crime no feminino. Rio de Janeiro: Relume Dumará: UFRJ, Núcleo de Antropologia da Política, 2001.

E-mail: rosemary.almeida@uece.br.

3 Professor, Secretaria de Educação do Ceará/SEDUC-CE. Mestre em Sociologia (UFC). Principal publicação: Liuro: Dez escolas, dois padrões de qualidade: uma pesquisa em dez escolas públicas de ensino médio do estado do Ceará (coautoria: André Haguette).E-mail: mkpceara@hotmail.com. 
Ferramenta didática ou guia curricular? Percepção de professores sobre o processo de escolha dos liuros didáticos de Sociologia em escolas do Ceará | Manoel Moreira de Sousa Neto, Rosemary de Oliveira Almeida e Márcio Kleber Morais Pessoa

didático-pedagógicas das obras. Há uma aproximação entre a divisão curricular aconselhada pelo Ceará, coleção Escola Aprendente (CEARÁ, 2008), e a forma como os professores escolheram os seus livros.

Palavras-chave: Livro didático. Currículo. Sociologia no Ensino Médio.

\section{Introdução}

A disciplina de Sociologia retornou, na última década, de forma oficial às escolas de Ensino Médio de todo o país, acatando a lei no $11.684 / 2008$, com caráter de obrigatoriedade. A situação em torno da implementação da disciplina é marcada por uma série de desafios relacionados à formação de professores, à proposta curricular, ao número de aulas, à situaçáo da escola pública brasileira, às mudanças no currículo da escola média brasileira, aos objetivos do Ensino Médio e, ainda, à produção de livros didáticos para a disciplina (MORAES, 2010).

Este texto pretende elaborar uma contribuição reflexiva, ainda inicial, sobre o processo de escolha dos livros didáticos de Sociologia em escolas públicas da rede estadual do Ceará. Para tanto, o trabalho enfoca questóes relacionadas à forma de escolha e apropriaçáo do livro didático de Sociologia, tendo como referência as percepções de professores a respeito da seleção do livro e do uso deste artefato em seis escolas da rede pública cearense, questionando quais critérios são utilizados pelos professores. Tomamos como parâmetro de estudo as categorias discutidas por Meucci (2014): topicalismo, nominalismo e contextualismo, visto que o livro didático pode ser apropriado pelo docente, por meio de seus recursos específicos de escrita e da exposição do conhecimento científico em âmbito escolar, de forma particular como referencial teórico para o conhecimento escolar daquela disciplina.

Partimos da hipótese de que o livro didático é utilizado como referência pelos professores no momento de construçáo do plano de curso para a disciplina nas escolas; dessa maneira, esse livro ultrapassa a condição de ferramenta auxiliar da prática pedagógica, tornando-se guia curricular de Sociologia no Ensino Médio, ainda que se constitua em um campo de tensóes como é o currículo. Entendemos, com efeito, que essa perspectiva se fortaleceu desde a inclusão da Sociologia no Programa Nacional do Livro Didático (PNLD) do Ministério da Educação (BRASIL, 2015c). Trata-se de um programa de 
avaliação e distribuição de livros didáticos para alunos de escolas públicas brasileiras.

O Programa Nacional do Livro Didático (PNLD) tem como principal objetivo subsidiar o trabalho pedagógico dos professores por meio da distribuição de coleções de livros didáticos aos alunos da educação básica. Após a avaliação das obras, o Ministério da Educação (MEC) publica o Guia de Livros Didáticos com resenhas das coleções consideradas aprovadas. O guia é encaminhado às escolas, que escolhem, entre os títulos disponíveis, aqueles que melhor atendem ao seu projeto político pedagógico. (BRASIL, 2015c).

Para o trabalho com dados empíricos, utilizamos informações da pesquisa de campo realizada mediante visitas a escolas públicas de ensino médio, com emprego de entrevistas semiestruturadas com professores da disciplina de Sociologia ${ }^{4}$, cada qual tendo optado por obras diferentes no PNLD 2015. Utilizamos um tópico guia ${ }^{5}$ - empregado para seguir uma agenda de perguntas e criar um referencial que facilite a discussão (GASKELL, 2013). Nosso tópico guia foi dividido em dois blocos de perguntas. O primeiro bloco foi relacionado ao trabalho do docente e a seu planejamento curricular; o segundo, ao processo de escolha do livro na escola em que ele trabalha. Este artigo é embasado em tais informaçóes, e também na análise de seis obras escolhidas no último edital do PNLD 2015 (BRASIL, 2015a) e sobre o guia para escolha dessas obras, produzido pelo Fundo Nacional de Desenvolvimento da Educação (FNDE) (BRASIL, 2014). As obras são: Sociologia em movimento (Editora Moderna); Sociologia Hoje (Editora Ática); Sociologia para o Ensino Médio (Editora Saraiva); Tempos Modernos, Tempos de Sociologia (Editora do Brasil); Sociologia (Editora Scipione); Sociologia para jovens do século XXI (Editora Imperial Novo Milênio). A ideia é, também, articular conteúdos encontrados nesses livros com aqueles destacados pela proposta curricular do estado do Ceará - o material da coleçáo Escola Aprendente (CEARÁ, 2008). Procedemos dessa forma por entendermos que esse recurso nos proporciona uma forma de mapear o processo de escolha dos livros com base em questionamentos fundamentados nos trabalhos relacionados ao tema (MORAES,

4 Foram realizadas seis entrevistas em seis escolas, com um professor de Sociologia de cada escola, no mês de maio de 2015.

5 O tópico guia é um roteiro sobre o que perguntar. "O tópico guia é parte vital do processo de pesquisa e necessita atenção detalhada [...]. Ele não é uma série extrema de perguntas especificas, mas ao contrário, um conjunto de títulos de parágrafos. Ele funciona como um lembrete par ao pesquisador [...]" (GASKELL, 2013, p. 64). 
2010; SANTOS, 2012, BEZERRA; MEUCCI, 2014), assim como conversaçóes preliminares com professores da Educação Básica.

A seleção dos docentes interlocutores se deu por meio de uma rede de contatos formada por nossa atuação na rede pública de ensino, a saber: o trabalho como docente e a atuação no Programa Institucional de Bolsas de Iniciação à Docência (PIBID) da Universidade Estadual do Ceará ${ }^{6}$. A partir desses contatos, buscamos docentes que participaram do processo de escolha dos livros durante o ano letivo de 2014. Dessa forma, a escolha ocorreu de forma aleatória, a partir do momento em que professores de escolas parceiras do PIBID ou de escolas próximas de nosso local de trabalho se disponibilizaram para participar.

Diante do quadro de desafios postos à Sociologia na Educação Básica, em especial àqueles relacionados à elaboração de um currículo mínimo e à produção de materiais didáticos, percebemos mudanças, ou seja, que muito já foi feito com o intuito de atender à demanda produzida pela reinserção dessa disciplina nas escolas (MORAES, 2010).

Contatamos, inicialmente, essa mudança mediante a observação de dois movimentos dos governos estadual do Ceará e federal, nos últimos anos. O primeiro relaciona-se ao alinhamento de conteúdos contidos na elaboração de propostas curriculares estaduais (SANTOS, 2012), que, apesar de não terem o objetivo de dialogar entre si, acabam por produzir um "denominador comum" para a distribuição dos conhecimentos da disciplina nas três séries do Ensino Médio. Em contrapartida, o Governo Federal, com esteio no Plano Nacional do Livro Didático (PNLD), avalia e distribui, desde 2012, livros de Sociologia para todas as escolas públicas do país. Segundo Bezerra e Meucci (2014, p. 92) ${ }^{7}$, a centralizaçáo dos conteúdos via PNLD acontece no mo-

6 O PIBID é um programa de formação de professores, voltado para o aperfeiçoamento e valorização dos professores da Educação Básica, já consolidado no Brasil, fomentado pela CAPES/MEC. Concede bolsas para alunos de licenciaturas de diferentes áreas de conhecimento, para professores da rede básica de ensino, denominados de professores supervisores e coordenadores de área, professores das universidades que participam de projetos de iniciação à docência desenvolvidos nas Instituições de Ensino superior. Dois autores deste artigo são professores do ensino médio do Ceará, dos quais um é professor supervisor do PIBID e a autora é coordenadora da área de sociologia do PIBID da Universidade Estadual do Ceará/UECE.

7 É importante ressaltarmos que o trabalho dos autores indica a produção e distribuição dos liuros didáticos como um dos elementos capazes de produzir um currículo comum. A esse fato, soma-se a presença de conhecimentos sociológicos no Exame Nacional do Ensino Médio (ENEM) e a maneira como as licenciaturas em 
mento em que são criados critérios técnicos de avaliação, ligados às áreas de conhecimento das Ciências Sociais, que são levados em consideração durante a produçáo dos livros que as editoras submetem à apreciaçáo dos pareceristas avaliadores indicados pelo MEC.

Com efeito, compreendemos, com base nesse movimento, que o livro didático transcende sua condição de ferramenta a ser utilizada durante a prática pedagógica e ganha status de matriz curricular a partir do momento em que ele acompanha a centralização de conteúdos proposta pelos governos por meio de matrizes curriculares e editais para a compra de livros. (BRASIL, 2015a).

Assim, nas entrevistas, contatamos que a distribuição dos livros aprovados no edital do PNLD 2015 às escolas foi fundamental para a escolha das obras. Para contextualizar esse processo, faremos, nos tópicos a seguir, uma breve discussão sobre a forma como os livros didáticos de Sociologia são produzidos e distribuídos no Brasil, a fim de compreender a maneira como estes chegam à apreciação dos professores nas escolas. Para tanto, os trabalhos de Meucci (2000, 2014), Sarandy (2004) e Cassiano (2013) serão fundamentais para o debate.

Percebemos, ainda, que a escolha do livro foi feita para atender, em primeiro lugar, à demanda que envolve quais conteúdos devem ser ministrados pela disciplina no Ensino Médio, em detrimento das características didático-pedagógicas que cada obra possui. Os dados analisados até o momento apontam que há uma relação de aproximação entre a divisão curricular aconselhada pelo estado, por meio das matrizes curriculares contidas na coleção Escola Aprendente (CEARÁ, 2008) e a forma como os professores escolheram os seus livros. Em outras palavras, quanto mais o conteúdo do livro se "adéqua" àquelas matrizes estaduais, maior será a chance de ser escolhido.

\section{Processo de institucionalização e intermitência da Sociologia nos currículos: é possível pensar um currículo?}

Antes de adentramos na discussão do livro didático propriamente dita - a qual, para este trabalho, é a base do currículo de Sociologia na formação de

Ciências Sociais formam os seus futuros professores, dando ênfase à transposição de conteúdos acadêmicos para o âmbito escolar (BEZERRA; MEUCCI, 20I4). 
planos de ensino dos professores -, elaboramos, neste item, uma discussão inicial sobre Sociologia e currículo, para nos engajar nesse debate nacional. Viu-se, historicamente, o processo de intermitência da Sociologia fazendo-a instituída de tempos em tempos e, em outros, instituindo-se na forma criativa e tensionada em alguns estados brasileiros, ora presente nos currículos, ora, ausente, ou, ainda, distribuída em temas em outras disciplinas. Nesse processo, foram criadas e já se contava com as Orientaçóes Curriculares Nacionais para o Ensino Médio: Ciências Humanas e suas Tecnologias (2006), como meio de adequar diretrizes para o ensino da Sociologia. Entretanto, somente com a definitiva legislaçáo em 2008 (Lei no 11.684/2008), institucionalizou-se e, de fato, consolidaram-se diretrizes para o ensino da Sociologia, gerando significativa representatividade necessária para se pensar um currículo da disciplina na escola básica. Consideramos que é importante chamar a atenção para esse interstício entre o documento e a institucionalização, como faz Oliveira (2013, p. 361):

Ainda que as OCN representem um avanço significativo na discussão em torno do ensino de Sociologia, nunca é demais relembrar que seu processo de elaboração se deu em período imediatamente anterior ao processo de reintrodução da disciplina em nível nacional, que só se substanciou na forma da lei no ano de 2008; logo, ainda que se trate de um pequeno interstício, este fator se apresenta como de extrema relevância, uma vez que cria um novo cenário institucional, em que a própria ideia de um currículo de Sociologia passa a ser repensada.

Quando pensamos em currículo, o que ele significa? Pensamos em um currículo nacional, em uma proposta no estado do Ceará? O que é, enfim? Definiçáo interessante encontramos no trabalho de Silva (2010, p. 14), visto que esse autor defende que importante é compreendermos que as teorias do currículo, sejam quais forem, pretendem "saber qual conhecimento deve ser ensinado". De uma forma mais sintética, a questão central é: o que deve ser ensinado? Esse autor acrescenta que, após as diferentes teorias responderem a essa questão, refletindo sobre a natureza da humanidade, dos processos de aprendizagem, da ciência e da cultura, outra informaçáo básica importante se faz presente: "[...] o que eles ou elas devem saber? Qual conhecimento ou saber é considerado importante ou válido ou essencial para merecer ser considerado parte do currículo?” (p. 14-15). Silva aprofunda essa discussão, lembrando, que ao perguntarmos "o quê?", evidenciamos o aspecto seletivo de conteúdos: "O currículo é sempre resultado de uma seleção" (p. 15), haja vista 
a quantidade de conhecimentos e saberes, a partir dos quais se selecionará aqueles que farão parte do currículo. Para o autor qualquer teoria deverá fazer este caminho seletivo e, ainda justificar suas escolhas. E, quanto à pergunta "o que deve saber", percebemos que ela é anterior à questão "o quê?", pois as teorias, mediante um processo dedutivo, já selecionam previamente o que consideram como conhecimento importante para determinadas pessoas (SILVA, 2010 , p. 15). Sobre isto, consideramos fundamental mencionar as seguintes perguntas do autor em sua reflexão para que possamos melhor compreender a conotação seletiva do currículo que vem das teorias:

Qual é o tipo de ser humano desejável para um determinado tipo de sociedade? Será a pessoa racional e ilustrada do ideal humanista de educação? Será a pessoa otimizadora e competitiva dos atuais modelos neoliberais de educação? Será a pessoal ajustada aos ideais de cidadania do moderno estado-nação? Será a pessoa desconfiada e crítica dos arranjos sociais existentes preconizada nas teorias educacionais críticas? A cada um desses "modelos" de ser humano corresponderá um tipo de conhecimento, um tipo de currículo. No fundo das teorias do currículo, está, pois, uma questão de "identidade" ou de "subjetividade". (SILVA, 20I0, p. 15).

Para Silva (2010), as discussōes do currículo empreendidas pensam apenas em conhecimento, quando, efetivamente, estamos falando daquilo que somos e nos tornamos no mundo vivido; por isso, consideramos ser uma questão de identidade e subjetividade.

Todas essas questóes se aproximam da discussão sobre o currículo de Sociologia - disciplina articulada aos saberes das Ciências Sociais, em suas conotaçóes antropológica, política e sociológica -, que se volta para a análise e a compreensão do ser individual e coletivo, das subjetividades e associaçóes, das diferentes práticas do indivíduo e das coletividades, tudo emaranhando em estruturas sociais e simbólicas do mundo da vida. Além do mais, trata-se de saberes profundamente compreensivos e críticos da realidade subjetiva e objetiva dos indivíduos e sociedades. Com base nos sentidos da Sociologia e nos questionamentos de Silva (2010), observamos possibilidades de debatermos sobre a elaboração de um currículo nacional em articulaçáo com o local, a fim de pensar em um currículo "para quem?, para quais cotidianos e contextos sócio-político, culturais e simbólicos?, para qual estudante de qual regiáo do país?”, e que contemple a diversidade das subjetividades, dos processos identitários. Enfim, são inúmeras perguntas que formam o "pano de fundo" sobre 
o que/o que deveria ser ensinado. Logo, nosso debate almeja discutir mais sobre o currículo de Sociologia como campo base para o avanço da disciplina no país, como também náo prescinde sobre a necessidade de dar voz aos sujeitos da escola, especialmente professores e gestores sobre a formação de seu currículo.

Urge pensar um currículo, estudar, falar dele, relacionar às diretrizes dos diferentes estados e de diferentes constituiçôes físicas e simbólicas de regiôes, de culturas, de políticas educacionais, bem como de subjetividades dos sujeitos do processo: os professores. É, de fato, muito complexo e de difícil unificação. Ainda estamos nesta fase de pensar, pois, como afirma Moraes $(2012 \text {, p. } 123)^{8}$ :

[...] nunca jamais houve uma proposta de ensino de Sociologia consagrada nacionalmente, senão, dezenas ou centenas, no mínimo, e infinitas, no máximo, presentes no cotidiano escolar, quando construídas por professores, nas propostas oficiais, elaboradas em cada gestão, ou nos próprios livros didáticos, a cargo de cada autor e a cada edição.

A ideia de estudiosos dessa área é aprofundar esses trabalhos, pois pesquisar propostas curriculares ainda é algo muito raro, há poucos estudos sobre o tema (MORAES, 2012). Como afirmam Maçaira, Montez e Gesteira (2015, p. 104), na pesquisa sobre currículo no Rio de Janeiro, houve intensificação das discussóes sobre o ensino da Sociologia, com a sua oficialidade; porém, esse campo de estudo ainda “[...] está começando a tecer diálogos mais perenes com o campo da Sociologia da Educação, em especial com as teorias do currículo".

Além disso, temos os documentos que nos servem de base e a pesquisa como meio de avançarmos no debate da constituição de um currículo, como afirma Oliveira (2013, p. 359):

Ainda que não haja atualmente um currículo nacional de Sociologia para o Ensino Médio, o que discutiremos mais adiante, isso não quer dizer que não haja referências que possam nortear minimamente a prática dos professores que lecionam esta disciplina. Nesta direção, possuímos dois marcos claramente postos: os Parâmetros Curriculares Nacionais e as Orientações Curriculares Nacionais.

8 Este trabalho de Amaury César Moraes faz um levantamento das propostas curriculares de cinco estados das regiões Sul e Sudeste com o intuido de realizar comparações e avaliar como tem sido a implantação da disciplina nas escolas (MORAES, 2012). 
Não podemos nos esquecer de citar que as Orientaçóes Curriculares Nacionais, em suas propostas construídas para o ensino de Sociologia, relacionam três recortes pilares para a constituiçáo do currículo: temas, conceitos e teorias que, embora se configurem como didaticamente separados, a orientação é que sejam "[...] tomados como mutuamente referentes, isto é, rigorosamente seria impossível trabalhar com um recorte sem se referir a outros" (BRASIL, 2006, p. 117). Ainda, seguindo as Orientaçóes Curriculares, uma formação efetiva volta-se para a pesquisa como mediadora da formação de professores, visto que será um elemento fundamental para a vida acadêmica e para a atuação reflexiva desses profissionais, em especial, aos que lecionam no Ensino Médio ao seguirem os três recortes: conceitos, temas e teorias.

A pesquisa deve estar presente nos três recortes, ou seja, ela pode ser um componente muito importante na relação dos alunos com o meio em que vivem e com a ciência que estão aprendendo. Assim, partindo de conceitos, de temas ou de teorias, a pesquisa pode ser um instrumento importante para o desenvolvimento da compreensão e para explicação dos fenômenos sociais. (BRASIL, 2006, p. 125-126).

O desafio permanente é percebermos como tudo isso se consolida na sala de aula, tendo em vista que "[...] os diversos sentidos que as categorias e teorias sociológicas assumem são trabalhados, considerando, dentre outros fatores, a formação docente e as condiçôes trabalho postas" (OLIVEIRA, 2013, p. 362). É nesse sentido que pretendemos entender a percepção dos professores sobre a escolha e a distribuição do livro didático - artefato de conteúdos, de métodos e recursos que possibilitem a mediação didática -, ou simplesmente, a imagem do currículo em construção no seu cotidiano escolar.

\section{A distribuição de livros de Sociologia no Brasil: dos primeiros manuais ao PNLD}

A produção e a distribuição de livros didáticos de Sociologia estão diretamente ligadas ao processo pendular de inserção e exclusão dessa disciplina nos currículos da Educação Básica brasileira.

Devemos frisar que a difusão do conhecimento sociológico no país aconteceu, primeiramente, na escola básica em meados da década de 1920, ocasião em que os livros didáticos cumpriram um papel importante nesse processo de inserção da Sociologia no Brasil. Uma vez inserida na escola secundária, a 
demanda por livros didáticos foi suprida pela importação de livros estrangeiros, vindos principalmente da França. Em seguida, surgiram os primeiros manuais brasileiros produzidos por intelectuais dedicados à Sociologia, incluindo alguns professores de escolas secundárias (MEUCCI, 2000).

No processo intermitente da Sociologia na Educação Básica, a partir da década de 1940, a disciplina deixou de ser obrigatória. Consequentemente, houve uma diminuição na demanda por livros nas escolas, o que fez com que as obras produzidas nesse primeiro momento de inserção da disciplina (décadas de 1920 a 1940) fossem reeditadas até meados da década de 1970, não havendo novas produçóes nesse período.

Com o retorno esporádico da disciplina às escolas, a partir da década de 1980 novos livros e manuais didáticos surgiram para atender à nova demanda, ainda que muitos deles não possuíssem um direcionamento para a Educação Básica. Era difícil traçar uma diferença entre os livros utilizados para a iniciação em cursos de graduação em Ciências Sociais daqueles utilizados em escolas médias (SARANDY, 2004).

Nesse sentido, levantamos a hipótese de que o fato de a Sociologia, na época, não estar consolidada nos currículos escolares fazia com que as editoras produzissem novos materiais com a finalidade de atender a um mercado9 fomentado pela distribuição em escolas públicas, como já acontecia com os livros de outras disciplinas da Educação Básica.

Convém salientarmos que esse mercado, que representa a maior parte dos lucros das grandes editoras brasileiras, é proporcionado pelo Plano Nacional do Livro Didático (PNLD) - que transforma o Estado brasileiro em um dos maiores compradores de livros do mundo (CASSIANO, 2013; MEUCCI, 2014).

Assim, a presença da Sociologia no edital lançado em 2011 para o triênio 2012/2014 fez com que os livros lançados a partir desse período tivessem um direcionamento específico para o Ensino Médio. Esse apontamento pode ex-

9 É importante esclarecermos que, durante esse periodo em que a Sociologia esteve ausente nas escolas, ocorreram diversas mudanças no processo de produção e distribuição de livros didáticos no Brasil. No início do século XX, esse mercado era essencialmente caracterizado por editoras familiares, isso quando os liuros não eram produzidos pela própria escola. A partir de 1985, com a criação do PNLD, a produção e distribuição de liuros escolares no pais migraram para o oligopólio de grandes grupos empresariais (nacionais e internacionais) ligados às telecomunicações (CASSIANO, 20I3). 
plicar o fato de que, no primeiro edital com a participação de obras de Sociologia, das 14 apresentadas, apenas duas foram aprovadas pelos técnicos pareceristas indicados pelo Ministério da Educaçáo (BRASIL, 2011). Já no segundo edital, que selecionou obras a serem distribuídas no triênio 2015/2017, das 13 obras que concorreram, foram seis os livros aprovados pela equipe técnica responsável pela seleção (BRASIL, 2014).

Além do número maior de obras selecionadas no último edital, podemos perceber a maior atençáo por parte das editoras em investir na produção de obras específicas para o Ensino Médio. Constatamos que a maior parte dos livros aprovados (quatro) pertence às editoras que mais lucram com a venda de livros escolares no Brasil. Segundo dados apresentados por Cassiano (2013, p. 40), o ranking das editoras por faturamento (em dólares) com dados referentes ao ano de 1998 aponta as editoras Ática (Sociologia Hoje) e Scipione (Sociologia) - as quais pertencem ao grupo Abril -, com o faturamento de 242 milhóes. Em seguida, aparecem: FTD, (não teve obra de Sociologia aprovada em 2015), com 129 milhóes; Saraiva (Sociologia para o Ensino Médio), com 81,8 milhóes; e a Moderna (Sociologia em Movimento), com 78 milhóes. As editoras do Brasil (Tempos Modernos, Tempos de Sociologia) e Imperial Novo Milênio (Sociologia para jovens do século XXI) náo aparecem na lista publicada pela autora.

Se analisarmos dados do faturamento (em reais) via PNLD, também visualizaremos os mesmos grandes grupos editoriais ocupando as primeiras colocaçóes. Das 22 editoras que tiveram obras aprovadas no edital, encontramos quatro que produziram livros de Sociologia: Ática (2a) e Scipione (6a), do grupo Abril educacional, e obtiveram um lucro que ultrapassa os 200 milhóes de reais. A Moderna ( $3^{a}$ ), que pertence ao grupo Santillana, alcançou lucros superiores a 160 milhóes de reais, e a Saraiva (4a), que também é proprietária das editoras Atual e Formato, obteve lucros superiores a 150 milhôes de reais. Das editoras que não estáo agrupadas em grandes conglomerados empresariais, há a Editora do Brasil (11a), com lucros superiores a casa dos 30 milhóes de reais, e a Imperial Novo Milênio (17a), com lucros superiores a 3 milhóes de reais. A tabela a seguir ilustra o faturamento das referidas empresas. 
Tabela I - Editoras que mais venderam livros no PNLD 2015

\begin{tabular}{|c|c|c|}
\hline Editora & Títulos adquiridos & Valor (em reais) \\
\hline FTD & 370 & | 83.697.292,6| \\
\hline ÁTICA & 246 & $182.153 .141,88$ \\
\hline MODERNA & 292 & $160.341 .696,95$ \\
\hline SARAIVA & 400 & $|53.952 .559,7|$ \\
\hline SM & 174 & $95.311 .612,46$ \\
\hline SCIPIONE & 194 & $62.963 .389,73$ \\
\hline IBEP & 150 & $61.600 .359,72$ \\
\hline TEXTO & 130 & $41.344 .398,76$ \\
\hline MACMILLAN & 12 & $38.085 .112,75$ \\
\hline AJS & 34 & $36.098 .215,55$ \\
\hline DO BRASIL & 100 & $34.973 .538,99$ \\
\hline POSITIVO & 136 & $31.469 .568,82$ \\
\hline ESCALA & 122 & $26.553 .600,65$ \\
\hline UDP & 8 & $16.301 .729,39$ \\
\hline BASE & 87 & $16.283 .759,46$ \\
\hline PAX & 2 & $5.701 .787,32$ \\
\hline IMPERIAL & 2 & $3.181 .521,80$ \\
\hline PEARSON & 22 & $2.335 .477,96$ \\
\hline CCS & 6 & $1.338 .547,79$ \\
\hline ZAPT & 6 & $1.086 .541,50$ \\
\hline SARANDI & 16 & $604.819,94$ \\
\hline GRAFSET & 10 & $427.165,35$ \\
\hline TERRA SUL & 8 & $|85.93|, 03$ \\
\hline ESFERA & 2 & $82.074,43$ \\
\hline Lê & 2 & $25.122,97$ \\
\hline
\end{tabular}

Fonte: Brasil (2015b).

Ao caracterizar-se como um negócio milionário para as editoras, a escolha dos livros transforma a escola no seu principal cliente, o que faz com que milhares de exemplares sejam enviados para as escolas a fim de que os professores tenham 
acesso a todo o material e não apenas ao parecer técnico e às resenhas encontradas no guia do $\mathrm{PNLD}^{10}$. Essa condição garante que os professores tenham acesso ao livro didático, para realizarem a escolha do livro, e que pelo menos alguns livros cheguem às escolas. Porém, isso desencadeia em uma prática de análise rápida e técnica do livro, visto que os educadores têm pouco tempo para avaliarem, e o fazem à mercê do gosto e tempo de cada um, sem que haja tempo anterior para uma leitura cuidadosa e estudo do Guia do Livro Didático. Esse documento (BRASIL, 2014) traz resumos dos livros, comentários significativos e detalha os critérios utilizados para a avaliação ${ }^{11}$, que podem contribuir com a escolha do livro na escola. São eles: 1. Critério de legislação; 2. Critérios teórico-conceituais; 3. Critérios didático-pedagógicos - conteúdos; 4. Critérios didático-pedagógicos - Atividades e exercícios; 5. Critérios de avaliação de imagens (fotos, ilustraçôes, gráficos, tabelas e mapas); 6. Critérios de editoração e aspectos visuais; 7. Manual do professor.

Durante o trabalho de campo, os docentes foram enfáticos ao afirmarem que ter acesso ao livro impresso possibilitou uma melhor orientação para a escolha da obra. Entretanto, fatores como o tempo, especialmente, não permitiram maior intimidade com o material apresentado. Além disso, dos seis professores entrevistados, apenas três tiveram acesso ao Guia e fizeram alguma leitura do material durante o período de escolha. Os demais sequer sabiam de sua existência.

Nós folheamos, nós analisamos vários critérios, né? É necessário nós estarmos com a obra [...] (Professora Maria ${ }^{12}-$ Sociologia).

Sim, com certeza! Agora a gente [sic] só lamenta que o tempo pra gente [sic]analisar não seja mais extenso, porque, às vezes, dava angústia... Sabe... De ter tanto liuro e o tempo tão curto pra gente [sic] poder fazer a escolha, né? E a gente [sic] não poder analisar o liuro com mais calma, ler os capítulos, né? Então, realmente, foi escolha um pouco atropelada. (Professor Leônidas - Sociologia para jovens do século XXI).

Assim, nós entendemos que ajuda, pelo fato de que você passa a ter acesso direto ao material, né? Você poder verificar o seu conteúdo, você poder verificar o seu formato... Que nós

10 O Guia do PNLD expõe informações sobre o processo de escolha e sobre as obras disponiveis em cada disciplina.

II Para aprofundar os critérios no documento, ver Brasil, 2014, p. 9-1I.

12 Optamos por não revelar a identidade de nossos interlocutores a fim de evitar sua identificação e possiveis constrangimentos advindos dos relatos aqui publicados. Para fins de organização, utilizaremos nomes fictícios seguidos do livro escolhido por sua escola, separados por travessão. 
Ferramenta didática ou guia curricular? Percepção de professores sobre o processo de escolha dos liuros didáticos de Sociologia em escolas do Ceará | Manoel Moreira de Sousa Neto, Rosemary de Oliveira Almeida e Márcio Kleber Morais Pessoa

achamos que isso também influencia no uso diário desses liuros pelos alunos. E, quando você está com o liuro em mãos, fica mais fácil pra [sic] se discutir e ter uma possibilidade de ter um acerto maior na escolha, na que a escola faz sobre o liuro didático. (Professor Renato - Sociologia em Movimento).

Com certeza, porque a gente pode comparar os capítulos [...]. (Professora Cinira - Sociologia Hoje).

Eu acho, assim... Que, até porque os professores ali... Ele tá escolhendo não só pra [sic] questão de ele trabalhar... Mas também um liuro que tenha uma, vamos dizer assim... Não vou dizer a didática [...] Mas que o professor possa trabalhar aquele conteúdo de uma maneira mais legal. Eu já entendo, já conheço o que o livro quer. A didática daquele que a gente [sic] vai utilizar, metodologia [...] E eu tenho certeza que você, conhecendo já a obra, facilita demais a você repassar esses conhecimentos, nem tenho dúvida disso. (Professor Ítalo - Sociologia para o ensino médio).

Sim, sim. Eu acho importante... O tempo é que não ajuda! (Professora Érica - Tempos Modernos, Tempos de Sociologia).

Cabe citarmos uma pesquisa que foi realizada no estado da Paraíba, ainda em relação ao PNLD 2012, em que os pesquisadores observaram o mesmo questionamento acerca do tempo e da ausência de estudo do Guia do Livro Didático:

Os professores, em tese, devem ter acesso ao Guia do Livro Didático, antes da escolha, mas o que a maioria desses professores relatou, é que tiveram dificuldades na escolha do processo de escolha do livro didático e não conseguiram ter acesso ao guia em tempo hábil. Isso implica, segundo, os entrevistados, numa escolha comprometida, já que, sem acesso ao guia, eles não entraram em contato com os resumos das duas obras selecionadas, e assim acabam por ter relação mais próxima com alguns livros de determinadas editoras e não de outras. (MELO; SILVA, 2015, p. 340).

Sobre a forma como esses livros chegaram às escolas, os professores relataram que as editoras os enviavam pelos correios, juntamente com coleçóes de outras disciplinas, como material de divulgação. É importante ressaltarmos que esse material não se resumia aos livros; também havia material de apoio ao professor - por exemplo, mapas, gráficos e a versão digital de alguns livros como parte do "pacote" entregue às escolas ${ }^{13}$.

13 É importante destacar que o Ministério da Educação, através da portaria normativa $n^{\circ} 7$ de abril de 2007. institui normas de conduta para os envolvidos no processo de escolha do livro didático, dentre elas, a 
A exceção a essa regra foi o livro "Sociologia para jovens do século XXP”, da editora Imperial, que chegava às escolas unicamente por meio digital através de contato direto do docente com a editora por correio eletrônico. Nas seis escolas visitadas durante o trabalho de campo dessa pesquisa, foi possível identificar o seguinte movimento de distribuição de exemplares para os professores:

Tabela 2 - Relação dos livros escolhidos e dos exemplares recebidos pelas escolas participantes dessa pesquisa - PNLD Sociologia

\begin{tabular}{cc}
\hline Livro escolhido & Exemplares recebidos \\
\hline Sociologia em Movimento & I, 3 e 4. \\
Sociologia Hoje & 2,3 e 4. \\
Sociologia para o Ensino Médio & I, 2, 3 e 5. \\
Tempos Modernos, Tempos de Sociologia & 2,4 e 5. \\
Sociologia & I, 2, 4 e 5. \\
Sociologia para Jovens do Século XXI & I, 2, 3, 4 e 6. \\
\hline
\end{tabular}

Legenda: I - Sociologia para o Ensino Médio; 2 - Sociologia Hoje; 3 - Sociologia em Movimento; 4 - Tempos Modernos, Tempos de Sociologia; 5 - Sociologia; 6 - Sociologia para jovens do Século XXI. Fonte: Elaborada pelos autores.

Como se pode apreender da análise da Tabela 2, todos os interlocutores dessa pesquisa escolheram livros somente entre aqueles aos quais tiveram acesso à edição impressa, ficando o Guia contendo informaçôes sobre todas as obras, relegado por aqueles que tiveram acesso (rememorando: somente três dos seis docentes tomaram conhecimento desse documento). Também identificamos que, entre os livros com divulgação por material impresso nas escolas pesquisadas, estáo aqueles com o número maior de adesôes no PNLD 2015 no Brasil e no Ceará, conforme ilustram as seguintes tabelas:

regulamentação da distribuição de material de divulgação às escolas. Portanto, a prática identificada durante a pesquisa de envio das obras impressas via postal não se configura como ilegalidade; porém, o fato de o Ministério não obrigar o envio de todos os liuros às escolas cria um cenário onde apenas algumas das obras selecionadas chegam até os professores em seu formato impresso. Mais detalhes em Brasil, 2007. 
Tabela 3 - Distribuição de livros de Sociologia no Brasil via PNLD 2015

\begin{tabular}{|c|c|c|c|c|}
\hline \multirow[b]{2}{*}{ Descrição } & Quantidade & Quantidade & Proporção & Proporção \\
\hline & $\begin{array}{l}\text { Escolas com } \\
\text { Escolha }\end{array}$ & Livros & $\begin{array}{l}\text { Escolas com } \\
\text { Escolha }\end{array}$ & Livros \\
\hline $\begin{array}{l}\text { SOCIOLOGIA PARA O ENSINO } \\
\text { MÉDIO }\end{array}$ & 3.621 & $1.173,673$ & $18,76 \%$ & $16,55 \%$ \\
\hline $\begin{array}{l}\text { SOCIOLOGIA HOJE - VOLUME } \\
\text { ÚNICO }\end{array}$ & 4.121 & $1.561,444$ & $21,36 \%$ & $22,01 \%$ \\
\hline SOCIOLOGIA EM MOVIMENTO & 5.679 & $2.273,756$ & $29,43 \%$ & $32,06 \%$ \\
\hline $\begin{array}{l}\text { TEMPOS MODERNOS, TEMPOS } \\
\text { DE SOCIOLOGIA }\end{array}$ & 2.551 & 980.155 & $13,22 \%$ & $13,82 \%$ \\
\hline SOCIOLOGIA - VOLUME ÚNICO & 2.586 & 861.062 & $13,40 \%$ & $12,14 \%$ \\
\hline \multirow[t]{2}{*}{$\begin{array}{l}\text { SOCIOLOGIA PARA JOVENS DO } \\
\text { SÉCULO XXI }\end{array}$} & 739 & 242.991 & $3,83 \%$ & $3,43 \%$ \\
\hline & 19.297 & $7.093,081$ & $100,00 \%$ & $100,00 \%$ \\
\hline
\end{tabular}

Fonte: Brasil (2015b).

Tabela 4 - Distribuição de livros de Sociologia no Ceará via PNLD 2015

\begin{tabular}{lcccc}
\hline & Quantidade & Quantidade & Proporção & Proporção \\
\cline { 2 - 5 } Descrição & $\begin{array}{c}\text { Escolas com } \\
\text { Escolha }\end{array}$ & Livros & $\begin{array}{c}\text { Escolas com } \\
\text { Escolha }\end{array}$ & Livros \\
\hline $\begin{array}{l}\text { SOCIOLOGIA PARA O ENSINO } \\
\text { MÉDIO }\end{array}$ & 81 & 36.978 & $13,11 \%$ & $11,04 \%$ \\
$\begin{array}{l}\text { SOCIOLOGIA HOJE - VOLUME } \\
\text { ÚNICO }\end{array}$ & 115 & 67.761 & $18,61 \%$ & $20,22 \%$ \\
$\begin{array}{l}\text { SOCIOLOGIA EM MOVIMENTO } \\
\text { TEMPOS MODERNOS, TEMPOS DE }\end{array}$ & 188 & 98.863 & $30,42 \%$ & $29,51 \%$ \\
$\begin{array}{l}\text { SOCIOLOGIA } \\
\text { SOCIOLOGIA - VOLUME ÚNICO }\end{array}$ & 157 & 82.377 & $25,40 \%$ & $24,59 \%$ \\
$\begin{array}{l}\text { SOCIOLOGIA PARA JOVENS DO } \\
\text { SÉCULO XXI }\end{array}$ & 28 & 31.357 & $7,93 \%$ & $9,36 \%$ \\
& 618 & 335.066 & $100,00 \%$ & $100,00 \%$ \\
\hline
\end{tabular}

Fonte: Brasil (2015b). 
Chamou-nos a atenção o fato de a única editora que não utilizou a divulgação de seus livros em material impresso ter ficado com as últimas colocaçóes considerando a escolha nacional, com apenas 739 escolas de um total de 19.297 em todo o país (3,8\%); e, no plano estadual, com 28 das 618 escolas $(4,5 \%)$ que participaram da seleção em $2014^{14}$.

Diante desse quadro, problematizamos a real autonomia que os professores têm durante o processo de escolha no PNLD, pois a análise dos dados aponta para a escolha por parte dos docentes condicionada à análise do livro impresso, material que chega até a escola por meio da intervenção opcional das editoras. Se há o entendimento por parte dos docentes de que a análise da obra impressa é importante, os que não tiveram acesso a todos os livros selecionados identificam o aspecto negativo de náo terem feito uma análise de todos eles, por meio do material impresso, como relata a professora Érica:

[...] eu escolhi o livro Tempos Modernos porque, das obras que vieram, chegaram três: Tempos Modernos, Sociologia Hoje e Sociologia. Até então, o Sociologia em Movimento, né?... Que, depois, eu percebi que era bem interessante trabalhar com ele... Só chegou, acho, que um mês depois [da finalização da escolha do PNLD lá na escola [...] (Professora Érica - Tempos Modernos, Tempos de Sociologia).

Dessa maneira, a análise que faremos sobre os critérios de escolha dos livros relacionados à conexão entre critérios técnicos das obras e os princípios ligados ao conhecimento escolar de Sociologia devem ser relativizados pelo leitor, visto que os professores tiveram apenas autonomia relativa para comparar e escolher esses materiais. Em um cenário hipotético, por meio do qual todos os professores tivessem acesso à obra impressa integral e em tempo hábil para se debruçarem em sua análise, com leitura anterior ao Guia do Livro didático, uma possível norma, imposta pelo Governo Federal às editoras, poderia contribuir para a análise que será realizada no tópico seguinte.

14 Em mensagem amplamente divulgada em fóruns etc., na internet, os autores do liuro Sociologia para jovens do Século XXI, Luiz Fernandes de Oliveira e Ricardo Cesar Rocha da Costa, justificam que o fato de terem publicado a obra por uma "editora com poucos recursos financeiros" fez com que divulgassem aquela mensagem. objetivando pedir a todos os interessados: "examinem atentamente" [...] divulguem esse trabalho [em formato digital PDF] entre todos os seus contatos" (Coletivo, 20 15, [s. p.]). Foi uma forma de tentar igualar a situação de seu livro com o das demais editoras que, possivelmente, enviaram exemplares impressos a todas as escolas participantes do PNLD. 


\section{4 papel do livro na construção curricular da disciplina nas escolas}

É possível perceber, por meio da análise do guia de Sociologia do PNLD 2015, que os seis livros aprovados atendem náo apenas aos critérios técnicos, comum às obras de caráter didático, mas também a alguns princípios que apontam o caminho para a consolidaçáo do conhecimento escolar de Sociologia, segundo o próprio documento. São eles: a interdisciplinaridade das Ciências Sociais, o rigor teórico conceitual, a mediação didática, a apreensão do conhecimento sociológico pelo aluno e a autonomia do trabalho pedagógico do professor (BRASIL, 2014, p. 8). Sáo esses princípios que dão o caráter centralizador do currículo ao livro didático, fazendo dele, mais do que uma mera ferramenta de apoio ao professor, uma referência curricular para a escola (BEZERRA; MEUCCI, 2014).

Esse caráter centralizador que o livro possui pode ser visualizado a partir do momento em que realizamos uma aproximação entre os princípios elencados pelo Guia e as orientaçóes curriculares estaduais concentradas no material Escola Aprendente (CEARÁ, 2008), quando se destacam as mesmas preocupaçôes quanto à interdisciplinaridade das Ciências Sociais, ao rigor teórico conceitual e à autonomia do trabalho do professor.

O plano curricular para o ensino de Sociologia no Ensino Médio [...] propõe que a primeira série do Ensino Médio ocupe-se da contextualização das Ciências Sociais, com destaque para a questão da pesquisa e trabalhe os conceitos dos autores clássicos da Sociologia como Durkheim, Weber e Marx; a segunda série analisa a política, o poder e a cidadania e a terceira série aborda o tema complexo da cultura na sua relação com a natureza, bem como os autores brasileiros clássicos das Ciências Sociais (Gilberto Freyre, Florestan Fernandes, Sérgio B. de Holanda, dentre outros) e suas abordagens sobre os graves problemas sociais brasileiros: desemprego, violência, pobreza, racismo, exclusão social etc. (CEARÁ, 2008, p. 74, grifos nossos).

Com efeito, essas aproximaçóes acabam por colocar as orientaçóes curriculares e o livro didático em um mesmo patamar para a definição curricular da Sociologia nas escolas. Nesse sentido, apresentaremos as percepçóes dos professores acerca desses princípios a fim de compreender quais "técnicas" utilizadas na escolha desses livros didáticos foram essenciais para a articulação entre a proposta curricular do estado do Ceará e a oferecida pela obra. Para 
nortear essa análise, faremos uso das categorias elencadas por Meucci (2014, p. 215-216) para a diferenciação das diferentes formas que a escrita em livros didáticos proporciona, são elas: o topicalismo, o nominalismo e o contextualismo. Utilizaremos essas categorias em contraste com as respostas que os docentes deram à seguinte pergunta: o que foi determinante para a escolha deste livro para a escola?

O topicalismo é a forma de organizar os conteúdos científicos em tópicos, com o intuito de demarcá-lo em lugar específico (MEUCCI, 2014). Com base nessa organização, o professor poderá planejar a divisão dos conteúdos nas três séries conforme a estruturação dos capítulos, incluindo aí a maneira como os tópicos estáo inseridos em cada capítulo. Esse tipo de organizaçáo pode ser identificado nas palavras do professor que decidiu pelo livro Sociologia para o Ensino Médio (editora Saraiva).

[...] esse liuro... Ele tem uma facilidade maior no quesito [relacionado à] questão de você poder [...] Eu pelo menos utilizo muito os slides... Que eu já tenho esse livro em formato de slides. Então, facilita, não só você lá, em sala de aula, fazendo uma leitura... Lógico que é interessante, mas... Você poder visualizar, mostrar para esses alunos, através desses slides... É... Eu acredito que seja uma ferramenta boa e facilita, de uma certa forma, o aprendizado deles. (Professor Ítalo - Sociologia para o Ensino Médio).

É importante ressaltarmos que o Professor Ítalo deu prioridade a essa característica porque o livro já havia sido adotado pela escola na edição anterior do PNLD. Logo, esse conhecimento prévio acabou fortalecendo o destaque dado à estruturação dos capítulos em tópicos.

Já o nominalismo é caracterizado pelo ato de nomear os fenômenos para possibilitar a sua compreensão por meio de conceitos científicos (MEUCCI, 2014). Essa característica foi determinante para a escolha dos livros Sociologia Hoje (editora Ática) e Sociologia (editora Scipione) por parte de alguns interlocutores. Na ocasiáo, as professoras destacaram o fato de a obra possibilitar o trabalho de fenômenos como o fundamentalismo e direitos humanos com o auxílio de conteúdos específicos, temas que, segundo as docentes, não foram encontrados em outras obras analisadas por elas.

Pronto, eu escolhi o livro porque ele tinha antropologia, né? Que eu achei mais interessante... Alguma discussão de gênero. E, aí... É como trabalho com direitos humanos. Eu peguei no final do segundo semestre. Agora, eu mudei o conteúdo e coloquei direitos humanos 
Ferramenta didática ou guia curricular? Percepção de professores sobre o processo de escolha dos liuros didáticos de Sociologia em escolas do Ceará | Manoel Moreira de Sousa Neto, Rosemary de Oliveira Almeida e Márcio Kleber Morais Pessoa

para o primeiro ano, e direitos humanos no final da terceira etapa para o segundo ano, $e$ direitos humanos no final da terceira etapa para o terceiro ano. Porque, como são 15 capítulos, os cinco capítulos para o ano todo era muito pouco. Então, durante uma das etapas, eu não uso liuro. Uso esses materiais extras de direitos humanos, porque, senão, cinco capítulos não dá. (Professora Cinira - Sociologia Hoje).

E aí... Alguns conteúdos mais bem trabalhados do que os outros... Principalmente, como eu disse, era o único que eu vi que trabalhou bem a questão de fundamentalismo, a questão do terrorismo. Veio com atividade que os demais não tinham. (Professora Maria - Sociologia).

O contextualismo apresenta esquemas teóricos de uma ciência descrevendo situações do cotidiano que exemplificam a abstração científica (MEUCCI, 2014). Nos livros de Sociologia, esse aspecto é proporcionado quando a escrita se aproxima do jovem estudante em uma linguagem adequada à sua realidade. Essa característica foi determinante para a escolha dos livros Tempos Modernos, Tempos de Sociologia (Editora do Brasil) e Sociologia em Movimento (Editora Moderna), por alguns professores, conforme eles próprios destacaram.

A questão da própria linguagem, porque os nossos alunos [...] tem a questão de a gente [sic] perceber a realidade da escola, dos alunos. Então, achei que o [liuro] "Tempos Modernos, Tempos de Sociologia” se encaixaria melhor (Professora Érica - Tempos modernos, Tempos de Sociologia).

Nós tivemos em Sociologia [...] É... Foram quatro autores diferentes, quatro obras, não... Três obras diferentes, pra que a gente [sic] pudesse, então, escolher e a escolha recaiu, então, sobre [o liuro] Sociologia em movimento; é por entendermos que a escrita do liuro atendia de uma forma mais simplificada as necessidades do Ensino Médio (Professor Renato - Sociologia em Movimento).

Por fim, ao justificar a escolha do livro Sociologia para jovens do século XXI (editora Imperial), o professor ressaltou aspectos da forma como a obra destaca a escrita nominalista e contextualista (MEUCCI, 2014), de acordo com a aproximaçáo que fizemos entre essas categorias e os princípios ligados ao conhecimento escolar de Sociologia elencados no guia do PNLD.

Bem... Em relação, por exemplo, a determinados conteúdos, que... No caso, por exemplo, do livro que a gente [sic] escolheu... Tinha conteúdos que não tinha em outros. Debate sobre gênero que tinha achado interessante... Que já trabalhava com os alunos dos primeiros anos... Que tinha nesse liuro. Então, a gente achou interessante alguns temas que não 
estavam em outros. E, também, por exemplo, a questão da linguagem do livro, a maneira como era escrito, se era acessivel aos alunos, a maneira como as palauras eram utilizadas, o tamanho dos capítulos. (Professor Leônidas - Sociologia para jovens do século XXI).

A fala do professor Leônidas, além de fazer aproximação entre o conteúdo do livro e os dois conceitos destacados, também chama a atenção pelo fato de o docente fazer referência aos mesmos conceitos que foram determinantes para a escolha de outros livros pelos professores Renato, Érica, Maria e Cinira, o contextualismo e o nominalismo. Não desconsiderando que a avaliação de cada profissional das obras pode ter atendido a critérios bastante pessoais acerca do que cada conceito significa, o fato de o professor Leônidas ter sido o único a ter acesso à ediçáo impressa de "Sociologia para Jovens do Século XXI", pode ter influenciado determinantemente em sua escolha. O que, conforme já destacamos, deve ser considerado para problematizarmos a autonomia de cada docente na escolha.

Mesmo com essa limitação, compreendemos que é por meio da aproximação entre as estratégias de escrita dos livros didáticos e os princípios elencados para a consolidação do conhecimento escolar de Sociologia que o professor estabelece o livro como categoria de referência curricular.

A relevância que o professor Ítalo deu à estruturação do livro em tópicos distintos, o que facilitou a apresentação dos capítulos por meio de slides, mostra como essa característica proporcionou a mediação didática do conhecimento sociológico, além de dar autonomia à prática pedagógica do professor.

Ao dar ênfase aos aspectos nominalistas dos livros, as professoras Cinira e Maria acabam por destacar a forma como esses livros atendem aos princípios da interdisciplinaridade, ao destacarem a presença de conteúdos específicos da disciplina Antropologia, por exemplo, além do rigor teórico e conceitual para a explicaçáo de fenômenos como o fundamentalismo e o terrorismo, com esteio em conceitos próprios das Ciências Sociais.

Quanto ao contextualismo - ressaltado pelos professores Renato, Érica e Leônidas, correspondente à linguagem apresentada pelos livros escolhidos por esses docentes -, notamos que indica que tais obras atendem às demandas desses educadores, que fizeram a escolha visando a melhor apresentar o conhecimento sociológico aos seus alunos. 


\section{Considerações finais}

Reconhecemos o fato de que o estudo dos atuais livros didáticos de Sociologia ainda é bastante recente, embora consideremos a intensificação dos estudos sobre a Sociologia no Ensino Médio. Sabemos, também, que pouco pode ser dito sobre a sua eficácia como ferramenta didática de apoio ao professor, mas nosso trabalho não teve este objetivo. Por outro lado, convém salientarmos que o contexto de produção e distribuição dessas obras muito tem a contribuir acerca da consolidação do conhecimento escolar de Sociologia por meio de um currículo mínimo capaz de orientar o planejamento dos professores no momento de construção da disciplina nas escolas.

Nesse sentido, foi possível que pudéssemos, minimamente, constatar que os livros didáticos possuem um papel fundamental na orientação curricular da Sociologia nas escolas pesquisadas. Constatamos que esse material transcende a condição de ferramenta didática, pois passa a ser, também, uma referência para a escolha de conteúdos que serão trabalhados em sala de aula. Sua importância consiste no fato de os professores adequarem seus planejamentos a fim de utilizarem os capítulos de acordo com a orientaçáo estadual encontrada na coleção Escola Aprendente (CEARÁ, 2008).

Nossa breve análise aponta uma questão que, no futuro, poderá contribuir para o aprofundamento deste debate. Primeiramente, chama-nos a atenção o fato de que a produção capaz de centralizar os conteúdos abordados nos livros didáticos, que é o guia do PNLD, não foi utilizada por metade dos professores entrevistados. Além disso, os professores que tiveram acesso a esse material durante o período de escolha afirmaram que a análise do guia era limitada em relação à análise da obra completa.

Logo, percebemos uma intensa pulverização do conhecimento sociológico na escola média, visto que a escolha do livro didático e a forma como os professores empregam o seu conteúdo costuma ser desregrada, havendo a prevalência de atitudes individuais na efetivaçáo dessas açóes. Além disso, o fato de os docentes terem acesso à edição impressa de somente alguns títulos, sem conseguirem ter acesso a outros livros didáticos durante o período de escolha do livro didático, sem dúvida, influenciou diretamente na opção de cada escola por esse material. 


\section{Referências}

BRASIL. Lei no 11.684, de 2 de junho de 2008. Altera o art. 36 da Lei no 9.394, de 20 de dezembro de 1996, que estabelece as diretrizes e bases da educação nacional, para incluir a Filosofia e a Sociologia como disciplinas obrigatórias nos currículos do ensino médio. Diário Oficial da Uniáo, Brasília, DF, 3 jun. 2008. Disponível em: <http://www.planalto.gov.br/ccivil_03/_Ato20072010/2008/Lei/L11684.htm>. Acesso em: 20 dez. 2015.

Ciências humanas e suas tecnologias: Secretaria de Educação Básica. Orientaçóes curriculares para o ensino médio. Brasília: MEC; SEB, 2006. v. 3.

Portaria Normativa no 7 , de 5 de abril de 2007. Dispóe sobre as normas de conduta no âmbito da execução dos Programas do Livro. Diário Oficial da uniáo, 9 abr. 2007. Disponível em: $<$ https://www.fnde.gov.br/fndelegis/action/UrlPublicasAction.php?acao=abrirAtoPublico\&sgl_ tipo $=$ PNT\&num_ato $=00000007 \&$ seq_ato $=000 \& v 1 r \_a n o=2007 \& s g l \_o r g a o=M E C>$. Acesso em: 1 jul. 2015.

Editais - PNLD 2015. 2015a. Disponível em: <http://www.fnde.gov.br/ programas/livro-didatico/livro-didatico-editais/item/4032-pnld-2015>. Acesso em: 26 jun. 2015.

Secretaria de Educação Básica. Fundo Nacional de Desenvolvimento da Educação.

Guia de livros didáticos: PNLD 2012: Sociologia. Brasília, DF: MEC, 2011.

Guia de livros didáticos: PNLD 2015: Sociologia. Brasília,

DF: MEC, 2014.

Fundo Nacional de Desenvolvimento da Educaçáo - Programa Nacional do Livro Didático - PNLD 2015: Ensino Fundamental e Médio - Valores Negociados para Livros Impressos e MecDaisy. 2015b. Disponível em: <http://www.fnde.gov.br/arquivos/category/35dados-estatisticos?download=9231:pnld-2015-valores-de-aquisicao-por-editora-ensinofundamental-e-medio >. Acesso em: 27 jun. 2015.

Programa Nacional do Livro Didático. Apresentação. 2015c. Disponível em: $<$ http://portal.mec.gov.br/index.php?Itemid=668id=12391option=com_contentview=article $>$. Acesso em: 14 jun. 2015.

BEZERRA, R. G.; MEUCCI, S. Sociologia e educação básica: hipóteses sobre a dinâmica de produção de currículo. Revista de Ciências Sociais. Fortaleza, v. 45, n. 1, p. 87-101, jan./jun. 2014.

CASSIANO, C. C. F. O mercado do livro didático no Brasil do século XXI: a entrada do capital espanhol na educação nacional. São Paulo: Editora Unesp, 2013.

CEARÁ. Secretária da Educação. Metodologias de Apoio: matrizes curriculares para o ensino médio. Fortaleza: SEDUC, 2008. (Coleção Escola Aprendente, v. 1). 
Ferramenta didática ou guia curricular? Percepção de professores sobre o processo de escolha dos liuros didáticos de Sociologia em escolas do Ceará | Manoel Moreira de Sousa Neto, Rosemary de Oliveira Almeida e Márcio Kleber Morais Pessoa

COLETIVO dos Professores de Sociologia - Maringá/PR - Livro didático Sociologia para Jovens do Século XXI no PNLD 2015. 2015. Disponível em: <https://groups.google.com/forum/\#!topic/ sociologiamaringa/r0uylMiLwSI>. Acesso em: 27 jun. 2015.

GASKELL, G.. Entrevistas individuais e grupais. In: BAUER, M. W.; (Org.). Pesquisa qualitativa com texto, imagem e som: um manual prático. 11. ed. Petrópolis: Vozes, 2013, p. 64-89. MONTEZ, Gabriela ; MACAIRA, J. P. ; GESTEIRA, B. M. Currículos em mudança: a prática do ensino de sociologia no Rio de Janeiro. In: Anita Handfas; Julia Polessa Maçaira; Alexandre Barbosa Fraga. (Org.). Conhecimento escolar e ensino de sociologia: instituiçôes, práticas e percepçôes. 1ed. Rio de Janeiro: 7 letras, 2015, p. 101-114.

MELO, M. S.; SILVA, V. G. da. Reconstituindo o processo de escolha do livro didático de Sociologia no estado da Paraíba. In: HANDFAS, A.; MAÇAIRA, J. P. (Org.). Conhecimento escolar e ensino de sociologia: instituiçóes, práticas e percepçóes. Rio de Janeiro: 7 Letras, 2015, p. 336-345.

MEUCCI, S. A institucionalizaçáo da Sociologia no Brasil: os primeiros manuais e cursos. 2000. 157f. Dissertação (Mestrado em Sociologia) - Instituto de Filosofia e Ciências Humanas, Universidade Estadual de Campinas, Campinas, 2000.

Notas sobre o pensamento social brasileiro nos livros didáticos de sociologia. Revista Brasileira de Sociologia, Sergipe, v. 2, n. 3, p. 209-232, jan./jun. 2014.

MORAES, A. C. Desafios para a implementação do ensino de Sociologia na escola média brasileira. Cadernos do NUPPS, São Paulo, ano 2, v. 1, p. 1-10, set. 2010.

- Propostas Curriculares de Sociologia para o Ensino Médio: um estudo preliminar. In. HANDFAS, A.; MAÇAIRA, J. P. (Org.). Dilemas e perspectivas da sociologia na educaçáo básica. Rio de Janeiro: E-apers, 2012. P. 121-134. p. 121-134.

OLIVEIRA, A. O Currículo de Sociologia na Escola: um campo em construção (e disputa). Espaço do Currículo, v. 6, n. 2, p. 355-366, maio/ago. 2013.

SANTOS, M. B. dos. Diretrizes Curriculares estaduais para o ensino de sociologia: em busca do mapa comum. Percursos, Florianópolis, v. 13, n. 1, p. 40-59, jan./jun. 2012.

SARANDY, F. M. S. A Sociologia volta à escola: um estudo sobre os manuais de Sociologia para o Ensino Médio no Brasil. 2004. 142f. Dissertação (Mestrado em Sociologia) - Universidade Federal do Rio de Janeiro, Rio de Janeiro, 2004.

SILVA, T. T. da. Documentos de Identidade: uma introdução às teorias do currículo. Belo Horizonte: Autêntica, 2010.

Recebido em: 10.07.2015

Aceito em: 20.10.2015 


\section{Didactic tool or curriculum guide? Teachers' perception on the process of choosing Sociology textbooks in the schools of Ceará}

\section{Abstract}

This article aims to understand the perceptions of Sociology teachers on the choice and use of textbooks in six public schools in the state of Ceará. It starts with the hypothesis that textbook is used as a reference by teachers to build the course plan and not as an auxiliary tool of pedagogical practice, becoming curriculum guide of Sociology in high school. We evaluated the criteria used by teachers for choosing the book with parameter in the categories: topicalismo, nominalism and contextualism (MEUCCI, 2014). We evaluated six works chosen in the National Program announcement Textbook (PNLD 2015) and interviews with subject teachers. We realized that the book's choice relates to the demand for contents for discipline instead of didactic and pedagogical characteristics of the works. There is a connection between the curriculum division advised by Ceará, collection Learner School, (Ceará, 2008) and how teachers chosen their books.

Keywords: Textbook. Curriculum. Sociology in high school. 